\title{
Video and social rehabilitation of persons with mental illness helps to structure everyday life: a qualitative study
}

\author{
Claus Ugilt Oestergaard ${ }^{1} \wedge$, Helle Spindler ${ }^{2} \wedge$, Birthe Dinesen $^{1 \wedge}$ \\ ${ }^{1}$ Laboratory of Welfare Technologies - Telehealth \& Telerehabilitation, Sports Sciences - Performance and Technology, Department of Health \\ Science and Technology, Aalborg University, Aalborg, Denmark; ${ }^{2}$ Department of Psychology and Behavioral Sciences, Aarhus University, Aarhus, \\ Denmark \\ Contributions: (I) Conception and design: All authors; (II) Administrative support: CU Oestergaard; (III) Provision of study materials or patients: \\ CU Oestergaard; (IV) Collection and assembly of data: CU Oestergaard; (V) Data analysis and interpretation: CU Oestergaard, B Dinesen; (VI) \\ Manuscript writing: All authors; (VII) Final approval of manuscript: All authors. \\ Correspondence to: Claus Ugilt Oestergaard. Laboratory of Welfare Technologies - Telehealth \& Telerehabilitation, Sports Sciences - Performance and \\ Technology, Department of Health Science and Technology, Aalborg University, Niels Jernes Vej 14, DK-9220 Aalborg, Denmark. \\ Email: coe@hst.aau.dk.
}

Background: Living with a mental disorder has a significant impact on everyday life. In 2018, one out
of every six adults, equivalent to $17.3 \%$ of the adult population of the European Union, had symptoms
of mental disorders. This paper focus on social rehabilitation of patients with mental illness who have
been discharged from hospital and who use video communication technologies in their rehabilitation in
collaboration with their social worker. The aim of this study has been to explore the experiences of persons
with mental illnesses who participated in a long-term video-based tele-social rehabilitation program, the
Video Assist.

Methods: The overall research strategy is the case study method. Data collection techniques are based on triangulation. Document analysis has been performed. Participant observation in homes of persons with mental using video with social workers (168 hours). Semi structured qualitative interviews with persons with mental illness $(n=13)$ has been conducted lasting between 30 and 60 minutes. Data were analyzed using NVivo 10.0.

Results: Experiences of persons with mental illness participating in the tele-social rehabilitation program are in themes: user friendly video technology, video created a new means of communication between citizen and social worker, feeling of surveillance by having the technology in the home, development of new coping strategies in everyday life and need for psychosocial support and training via the video technology.

Conclusions: Persons with mental illness who are in a recovery process find that participating in a telesocial-rehabilitation program gives them a sense of mobility, security, surveillance but the ability to develop new coping strategies in their everyday lives. Future research is needed on long-term effects of tele-social rehabilitation for persons with mental illness.

Keywords: Video communication; tele-mental health; recovery; mental illness; social rehabilitation

Received: 02 April 2021; Accepted: 11 August 2021; Published: 20 January 2022.

doi: $10.21037 /$ mhealth-21-14

View this article at: https://dx.doi.org/10.21037/mhealth-21-14

^ ORCID: Claus Ugilt Oestergaard, 0000-0002-6771-4089; Helle Spindler, 0000-0002-7098-5699; Birthe Dinesen, 0000-0001-5893-9676. 


\section{Introduction}

Living with a mental disorder has a significant impact on everyday life. In 2018, one out of every six adults, equivalent to $17.3 \%$ of the adult population of the European Union (EU), had symptoms of mental disorders (1). Without effective treatment and support, mental health problems can have a devastating effect on people's lives (2).

The use of information technologies, termed "telepsychiatry", has affected the practice of psychiatry for more than three decades. Telepsychiatry can be defined as: "the provision of psychiatric care at a distance through technologies including phone care, Email, web-based systems and mobile applications" (3).

The USA, Canada and Australia have been early adopters of telepsychiatry. In 2010, there was insufficient scientific evidence regarding the effectiveness of telepsychiatry Gracia et al. (2010) (4). A later review by Gaebel et al. (2020) (5) on telepsychiatry conclude that it is mainly video consultations between clinicians, patients and families that have been used, that there was high patient and provider satisfaction, and that outcomes were equivalent to in-person care. Hilty et al. (2013) (6) conclude that telemental health was effective for diagnosis and assessment across many populations and for disorders in many contexts, such as emergency and home health.

In Europe, telepsychiatry is at an early stage, with predominantly pilot studies prior to the COVID-19 pandemic (7). The existing literature prior to the pandemic shows that research has focused mainly on telepsychiatry involving treatment and interventions of mental illness (8).

In Denmark, psychiatric hospitals are responsible for the treatment of patients with mental illness. When patients are discharged, treatment is relinquished to the municipality, which takes responsibility for the social rehabilitation of the patients. Municipal social workers assist the persons with mental illness in trying to return to everyday life and avoiding re-admission to hospital (9).

In the current project, we focus on the social rehabilitation of patients with mental illness who have been discharged from hospital and who use information and communication technologies in their rehabilitation, in collaboration with their social worker, a process we call 'tele-social-psychiatry'. The technology used in this study was a video communication system connecting persons with mental and their social workers, called 'Video Assist'. The aim of this study is to explore how people with mental illness in social rehabilitation experience using video communication as a part of a tele-social-rehabilitation program.

Reviews of the literature within technology-based interventions in social work practice indicate that technologybased interventions may be associated with improved mental health outcomes $(9,10)$. However, further research is needed within this area.

We have identified only one other study that focuses on social psychiatric tele-rehabilitation within a municipality framework (de Wit et al., 2015) (11). The study concluded that implementing web-based video technology supports people undergoing rehabilitation for a mental disorder, as they experience less dependence on their social worker and improve their everyday functions.

The aim of this study has been to explore the experiences of persons with mental illnesses who participated in a longterm video-based tele-social rehabilitation program, The Video Assist.

We present the following article in accordance with the COREQ reporting checklist (available at https://dx.doi. org/10.21037/mhealth-21-14).

\section{Methods}

\section{Recovery approach}

As its theoretical point of departure, this study employs the theory of recovery. Anthony (12) defines recovery as by Anthony in 1993: "Recovery is described as a deeply personal, unique process of changing one's attitudes, values, feelings, goals, skills, and/or roles. It is a way of living a satisfying, hopeful, and contributing life even with limitations caused by illness. Recovery involves the development of new meaning and purpose in one's life as one grows beyond the catastrophic effects of mental illness."

The social recovery process is measured relative to the individual's social functioning at work, in relationships with family, friends and social support workers, etc. In this study, the focus is on the social recovery process as it unfolds within the framework of a tele-social rehabilitation program.

\section{The tele-social psychiatry rehabilitation program}

Based on user-driven innovation (13) among persons and staff members in the Danish municipality of Esbjerg (pop. 116.000), a tele-social rehabilitation program was developed. The purpose of the program was to support the individual citizen's recovery process following discharge 


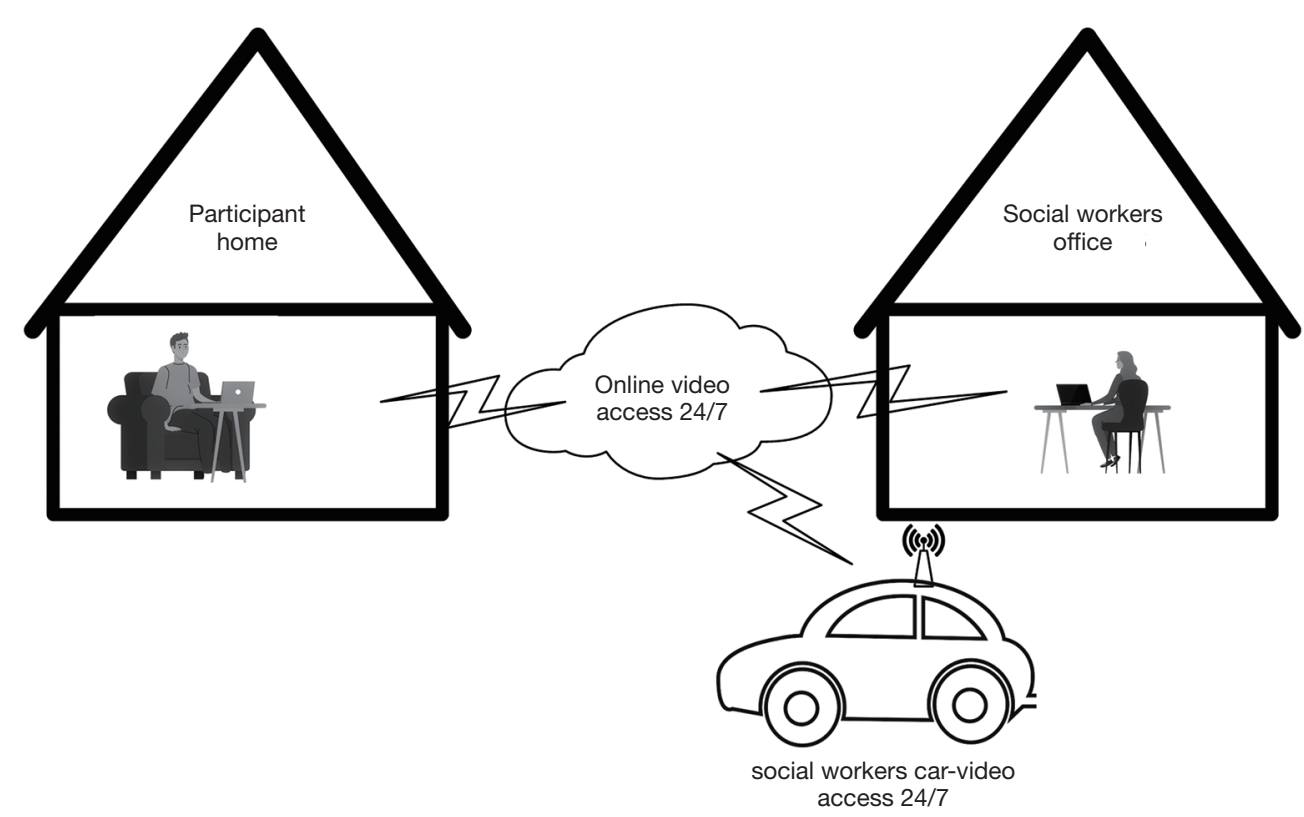

Figure 1 The technical setup of Video Assist, where participants were either using a laptop PC or a video screen based on a touchscreen.

from a psychiatric hospital with the aim of returning to everyday life. Based on the person's level of functioning and needs, an individualized plan was developed for the client's social rehabilitation. Each client had access to a secure video conference system, called Video Assist, allowing them to communicate on a $24 / 7$ basis with a social worker who would be on call 24 hours per day, either in their office or in their vehicle (Figure 1).

Video Assist functioned via a secure and encrypted line, facilitating video calls between a person with mental illness undergoing social rehabilitation and a social worker. The goal of the Video Assist system is to serve the mentally ill persons in the following ways:

(I) Video Assist served as a personal support tool when the person was experiencing an acute crisis, such as hearing voices, experiencing hallucinations, had suicidal thoughts, etc. When this occurred, they could obtain immediate video access at any hour of the day or night to a social support worker on duty who assisted in calming down the patient by talking to them via the Video Assist.

(II) Video Assist served as a personal practical tool in the rehabilitation process supporting the person undergoing social rehabilitation and the social worker, when meeting regarding practical information such as remembering appointments, help in paying bills, taking medicine.
(III) Video Assist also served as a monitoring channel enabling social workers to access the person with mental illness from their office or their car when driving in the district via a secure internet connection.

The persons with mental illness choose between two types of screens for video communication: (I) a touch screen that can be used only for video communications, which was preferred by participants with few IT skills; (II) a traditional laptop PC with installed video software. Participants could also install software on this PC, such as word processing software, or streaming software for watching videos on the internet. In this way, the Video Assist program could be integrated into clients' everyday use of IT. Those persons with good IT skills preferred this solution. Completion of the tele-social rehabilitation program was planned individually for each person with mental illness. Some persons with mental illness decided to quit after six months, and one continued for 18 months. The Video Assist software used in the current study was provided by a Danish company.

\section{Research strategy}

The overall research strategy in this study is the case study method (14). Data collection techniques are based on triangulation of several sources of data, all centered around 


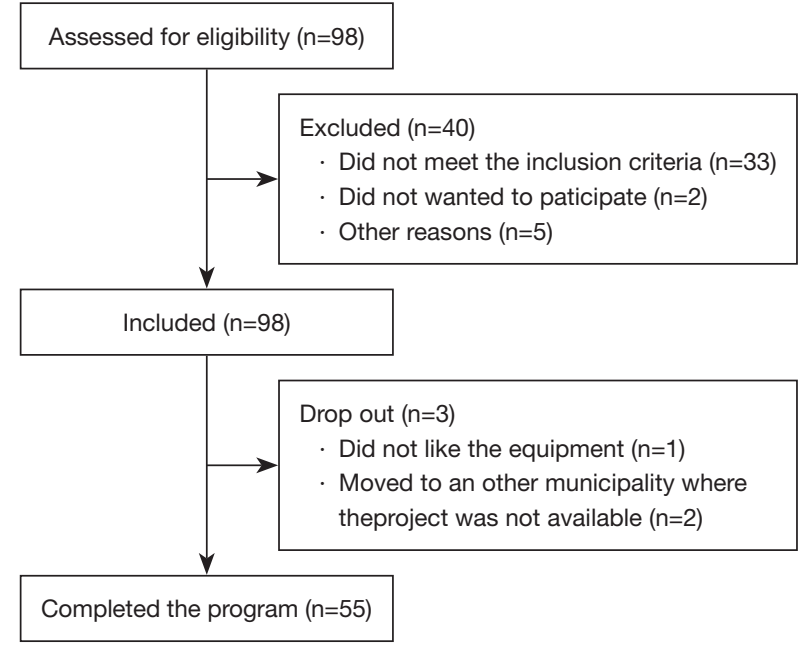

Figure 2 Recruitment of participants for the experiment.

the individual case, such as document analysis, participantobservation and qualitative interviews with the participating clients, all of whom had been treated for some kind of mental disorder. Data collection will be elaborated in the following sections.

\section{Ethical approval}

According to the Ethics Committee in the Region of North Jutland, Denmark (May 31 2013), the current study did not need ethical approval because the study did not involve any kind of new treatment for persons with mental illness. A data agreement between the partners in the project was signed. The study was conducted according to the Declaration of Helsinki (as revised in 2013). All participants signed informed consent agreements. The project was carried out between August 2013 and August 2016.

\section{Recruitment of participants}

Criteria for enrolling subjects in the tele-social rehabilitation program were as follows. Inclusion criteria: (I) persons diagnosed following the WHO's ICD-10 (15) criteria of depression, bipolar disorder (F30-39) or schizophrenia and paranoia (F20-29); (II) persons with mental disability who do not have the capacity to take care of their own needs and who receive social assistance in everyday life according to the Danish Act on Social Services; (III) the persons must be over 18 years of age and not incapacitated; (IV) have been admitted a psychiatric ward within the last year before enrollment; (V) lives in their own home; (VI) has a feeling of anxiety or is uncomfortable about being in their own home; (VII) receives two or more home visits from the staff per week. Exclusion criteria: (I) physical disabilities; (II) mental retardation (ICD-10; F70-F79).

Persons were recruited to the study by referral from their social workers (Figure 2). The persons with mental illness were first asked if they might be interested in participating in the trial voluntarily. They were then informed about the trial verbally by the social workers and by letter. If the person was interested in participating, he or she was invited to visit one of Esbjerg municipality's social service facilities to see and try out the Video Assist solution. Following this visit, the subjects where asked if they would like to participate in the trial by the project manager. A letter of consent was signed by the person. On agreeing to participate, a meeting was set up to install the video equipment in the individual's home.

The project recruited a total number of $n=58$ adult participants, 3 persons with mental illness dropped out of the program and 55 completed the program, 30 females average age 35.3 (22 to 67) and 25 males, average age 38.9 (19 to 67). The 55 participants suffered from a variety of mental disorders, including depression, bipolar disorder, schizophrenia and paranoia. During the recruitment process, one person pulled out of the trial, referring to his paranoia. Each participant had a video-based communication system installed in their home in order to communicate with their social worker. Each citizen used the system for a period of 6-18 months.

\section{Data collection}

A triangulation of data collection techniques has been used in order to provide multiple sources of evidence (14) in the case study. The following data collection techniques were used. The first author (male) has a Master's in science and is a $\mathrm{PhD}$ student at the time the study took place, has collected both data for participant observations and interviews and is experienced in qualitative data collection. No other persons except the researcher and the participant were present during the data collection. No relationship was established to the participants before the data collection started, and the participants was informed about the aim of the study and that the interviewer was a $\mathrm{PhD}$ student.

\section{Documents}

Documents as policies, planning documents, webpages and 
Table 1 Code tree

Use of technology
Ease of use
Acceptance
Challenges using the technology
$24 / 7$ online access to the social workers
Participant's experiences
Video as a communication tool between citizen and social
worker
Experiences using video
Video and everyday life
Psychosocial support and training via the technology

brochures from the municipality's rehabilitation center were reviewed in order to obtain knowledge and understanding of the context for the social rehabilitation of mental ill persons.

\section{Participant observation}

The study was designed so that each of the 55 participants was visited by the researcher (the first author) three times during the period in which they participated in the telesocial rehabilitation program. The first visit took place on the day when the video equipment was installed in their home; the second visit took place three months into the trial; and the third visit took place at the end of trial. The three personal visits had two main objectives: (I) (Delamont, 2007) (15) to obtain a basic understanding through participant-observation into the lives of persons with mental with mental illness; (II) to assess the individual's progress in recovery while participating in the tele-social rehabilitation program. An observational guide based upon recovery theory (16) was developed and this guide served as a framework for the observations. A total of 168 hours of participant observation was carried out and documented in a word file after each visit. The visits lasted between 45 and 60 minutes each. Observation notes were taken and documented in a MS-Word file.

\section{Interviews}

An interview guide based upon the recovery theory and an explorative approach was developed, pilot tested and implemented. The first author carried out the interviews. A total of 13 qualitative interviews, inspired by Kvale and Brinkmann (in 2009) (16) were carried out in order to obtain a deeper understanding of the participants' attitudes and experiences while participating in the tele-social rehabilitation program. During the interviews reflective questions were asked in order to secure that the participants had understood the questions and the interviewer had understand the answer of the questions.

Thirteen interviews were conducted at the first visit and again 13 at the end of the program. The first author carried out the interviews. The following criteria were used in order to select the interview participants: (I) consecutively after one year of start of study; (II) men and women selected in random order; (III) variation in diagnosis; (IV) variation in age.

The participants were approached face-to face in their homes for the interviews. The interviews were carried out between August 2014 and August 2015 until data saturation was reached and discussed with last author. Field notes were taken during the interviews and documented in a word file. For more information on the interviewees and their characteristics (Table 1). The interviews lasted between 30 and 60 minutes, and were recorded on a digital recorder and then transcribed. Please see Figure 2 for following the patient recruitment and drop outs.

\section{Data analysis}

Using NVivo 10, the transcribed data from the participantobservations, field notes during interviews and the interviews has been analyzed by the first and third author in steps inspired by Kvale and Brinkmann (in 2009). A combination of deductive and inductive strategies was used to analyze the data. Based on key definitions and concepts (in vitro nodes) from the recovery theory framework and from interviews (in vivo nodes), the code tree was constructed. The code tree is illustrated in Table 1 .

When formulating the concepts from the respondents, observation notes and qualitative interviews were studied and coded based on initial impressions. Based on these first impressions, concepts of respondents in the qualitative interviews were then examined and coded. The next steps consisted of a rough encoding followed by a more refined coding based on analysis of the coded data and subsequent adjustments. The key themes and patterns relevant to the participants' experiences with tele-social rehabilitation were then identified. 
Table 2 Interviewed persons' characteristics

\begin{tabular}{|c|c|c|c|c|c|}
\hline Participant ID & Gender & $\begin{array}{c}\text { Age at } \\
\text { beginning } \\
\text { of trial }\end{array}$ & Diagnosis/ICD-10 & $\begin{array}{c}\text { Experience as PC } \\
\text { user }\end{array}$ & $\begin{array}{l}\text { No. of weeks } \\
\text { participating in } \\
\text { the project }\end{array}$ \\
\hline Citizen ID 17 & Female & 51 & Schizophrenia (F20-F29) & Modest & 30 \\
\hline Citizen ID 18 & Female & 24 & Schizophrenia (F20-F29) & Limited & 58 \\
\hline Citizen ID 11 & Male & 27 & Schizophrenia (F20-F29) \& paranoia & Limited & 28 \\
\hline Citizen ID 05 & Female & 41 & Schizophrenia (F20-F29) \& bipolar disorder (F30-F39) & Modest & 47 \\
\hline Citizen ID 03 & Female & 38 & Schizophrenia (F20-F29) \& bipolar disorder (F30-F39) & Limited & 72 \\
\hline Citizen ID 07 & Female & 39 & Schizophrenia (F20-F29) \& depression (F30-F39) & Limited & 62 \\
\hline Citizen ID 12 & Male & 33 & Schizophrenia (F20-F29) \& bipolar disorder (F30-F39) & Limited & 61 \\
\hline Citizen ID 25 & Male & 34 & Schizophrenia (F20-F29) & Very experienced & 42 \\
\hline Citizen ID 09 & Female & 60 & Schizophrenia (F20-F29) & Modest & 29 \\
\hline
\end{tabular}

This final phase of the analysis was a detailed interpretation carried out in the context of the participants' understanding. In this phase, the interviews were analyzed to identify the participants' experiences and perceptions. The coding and analysis were carried out by the first author and discussed with the two other authors.

\section{Results}

\section{Interviewed persons' characteristics}

Table 2 describes the characteristics of the interviewed persons with mental illness included in the study.

The males ( $\mathrm{n}=5)$ average age was 32.4 (27 to 39$)$ and the females $(n=8)$, average age was 37.8 (22 to 60 ).

The period during which the participants used the Video Assist system extended over a period of a minimum of 26 weeks, with the maximum period being 72 weeks. The average time for participation, the trial was 46 weeks.

Table 3 describes the themes and sub-themes from the analysis.

\section{User-friendly video technology}

The video technology introduced for the persons with mental illness was regarded as acceptable for use and user- friendly. The participants stated that they found the video technology gave them increased mobility in their everyday life. One person expressed:

"The monitor or laptop is easy to use." (ID 17).

"I was unsure if I could use the video solution, but it has proven to be simple." (ID 11).

Observations revealed that many participants began to take their laptop PC on extended trips to their families, so that they could contact the social workers via video in case they experienced moments of anxiety or crisis.

\section{Video creates a new means of communication between person with mental illness and the social worker}

Some of the interviewed participants expressed feelings of insecurity before participating in the study, now that they were alone at home. By giving the participants video access to the staff on a $24 / 7$ basis, the participants felt more secure and less anxious. One participant stated: "It gave me a feeling of security to get the equipment set up in my home." (ID 03).

Visual contact with the social support worker is essential for the participants. The participants stated that they preferred to interact with the staff on a face-to-face basis. This preference is partly due to the fact if they 'hear voices' 
Table 3 Experiences of persons with mental participating in the tele-social rehabilitation program (based on participant-observation and interviews)

\begin{tabular}{ll}
\hline Themes & Sub-themes \\
\hline User friendly video technology & Acceptance and ease of use of the equipment \\
& Increased mobility in everyday life \\
Video created a new means of communication between citizen & Feeling of security \\
and social worker & Visual contact with the social worker is essential \\
& Persons with mental illness can contact social workers 24/7 \\
Feeling of surveillance by having the technology in the home & The technology in the homes is a reminder of illness \\
Development of new coping strategies in everyday life & Developed routines to prevent re-admission to mental hospital \\
Psychosocial support and training via the distance technology & Online training sessions are being implemented \\
\end{tabular}

as part of their illness, it helps them to see the social worker when they have conversations. Observations of video calls support the interview data, as the participants was more relaxed during the video calls than during ordinary telephone calls. As such, the video conversations gave them a sense of calm and intimacy that could not be obtained when using an ordinary phone.

"It is a positive change for me that I can see the person whom I am talking to." (ID 03).

The ability to be able to contact the social support worker at any time of the day or night gave participants an additional feeling of well-being.

"I am often afraid at night. A daily video call from the staff and the possibility to call the staff at night is a useful belp for me." (ID 07).

\section{Feeling of surveillance by having the technology in the bome}

The participants expressed that the technology in the homes is a reminder of their illness. From our home observations, we found that it was especially those persons who had a video screen with a touch screen who felt most reminded of their illness. The presence of the screen gave them a feeling of surveillance, of "living with a mental illness".

"The video monitor is not a design icon. It reminds me that I am sometimes very ill as well as possible surveillance." (ID 25).

"I bide my mental illness from my friends. It gives me a feeling of surveillance having a white monitor standing in my living room, and my guests ask what I use it for." (ID 13).

\section{Development of new coping strategies in everyday life}

The analysis of interviews also revealed a sub-theme: the technology helped participants to develop routines that could prevent re-admission to mental health facilities.

"When I have suicidal thoughts, I use the video conference for a conversation with the staff. Previously, I would have gone to the bospital to be admitted." (ID 18).

"Previously, I had several admissions to the mental hospital in a year. Now I have developed a routine where my laptop $P C$, with video software installed, is placed beside my bed at night. When I feel insecure, I first wait five minutes to get a sense of security. If that doesn't help, I turn on my laptop and watch a video-very often I find rest. If not, I call the staff for a video conversation during the night. During the last 12 months, I have been to the psychiatric hospital only once." (ID 05).

\section{Psychosocial support and training via the distance}

By making use of video communication, both the participants in the trial and the social workers experienced a change over time. At the beginning of the trial, observations showed that the social workers made a number of calls to the participants just to put them at ease. Over time, the video calls changed character, and online rehabilitation, were being implemented. The home visits were gradually replaced by virtual visits. As one participant explained: "I find it very difficult, for example, to look at myself, in a mirror or my reflection in a shop window or my own picture on a video screen. The social workers work with me so I can learn to see my own reflection. At first, I was always standing next to the video screen and talking to social workers. At one point we agreed that 
they would only speak to me if I showed myself in front of the camera. Today it is going well, I can stand longer and longer and see and talk with the social workers. That's a good help for me." (ID 21).

During the early period of the trial observations, we observed that that several of the participants were visited in their homes by the social workers every day. Observations and interviews showed that especially in the evenings, participants found the visits disorienting. These evening visits were therefore replaced by virtual visits. As one participant explained.

"It's nice in the evening that a virtual visit takes only a minute. The social workers ask me how I feel and wish me a good night. I feel good about that." (ID 03).

\section{Discussion}

\section{Principal/primary results}

The aim of this study was to describe how persons with mental illnesses experienced a tele-social rehabilitation program based upon a recovery approach. A triangulation of data collection techniques was used. The participants found the video technology to be user-friendly. For them it created a new way of communication, a sense of security, but also a feeling of surveillance by having the technology visible in their home. The parsons in the study also developed new coping strategies when using the technology as part of their everyday life. Over time, the psychosocial support and rehabilitation was transferred from real life and implemented into the Video Assist program.

Reviews of telemedicine interventions for persons with mental disorders by Bashshur et al. (17), Hubley et al. (18) conclude that telepsychiatry has gone beyond the pilot stage and in the U.S. is now being implemented as a standard part of clinical practice. Reviews reveal that patients accept the technology, attain a higher quality of life, and that it is cost effective

A review by Fletcher et al. (in 2018) (19) found that patients of varying demographics and range of mental health conditions expressed high rates of satisfaction with receiving therapy via video at home. Fletcher et al. concluded that using video technology is an accepted technology for persons with mental illness, both in treatment of in a rehabilitation context.

These reviews are in line with the findings of the present study and with the Dutch study of municipalbased rehabilitation conducted by de Wit et al. (in 2015).
The latter study also found that persons with mental illness participating in social psychiatric tele-rehabilitation in a municipality framework felt more secure being able to contact their coach at any time, experienced increased control, saved time and experienced greater flexibility in their scheduling (11). In contrast to the current study, de Wit et al.'s study was a feasibility study, however, it is the only study identified that is comparable to our Video Assist trial in Esbjerg. We have not identified other studies within social psychiatric tele-rehabilitation.

In our study, some participants felt that having a video screen visible in their home gave them a feeling of surveillance. Participants stated that it gave them a reminder that they were mentally ill. Our study was carried out from 2014 and 2016. Since then, the technologies have been developed that are smaller and less intrusive, enabling them to blend in to people's home environment and their everyday life. How et al. (in 2016) (20) point out that in designing cognitive telerehabilitation technologies for patients with traumatic brain injury, developers should consider how these technologies can be best adapted to a patient's physical, cognitive and emotional state (21).

Participants in the tele-social-rehabilitation program stated that the program helped them develop a sense of security and new coping strategies in their everyday lives. They also expressed that they had developed new everyday routines that helped them avoid having to be re-admitted to hospital. The experience of security in conversations via video is also an observation mentioned in studies by Calvillo (21) and Campbell (22). de Wit et al. (11) reported on positive effects on the levels of independence among clients, but their study did not find changes in quality of life or empowerment (9). de Wit and our study use only a small sample, so there is a need for further research on the overall efficacy of tele-social-rehabilitation programs.

Historically, little research has been performed on the integration of technology into direct social work practice. A systematic review by Ramsey \& Montgomery (8) describes a range of studies on the implementation of innovative technologies with the aim of addressing the mental health needs for a wide variety of populations, settings, and presenting symptoms. In our study, the social workers used the video for psychosocial support and rehabilitation via distance. We have not identified other studies that used this method. The COVID-19 pandemic has stimulated the use of digital technologies within healthcare and social work. We can thus expect more studies on the benefits and drawbacks of using digital technologies in social psychiatric 
tele-rehabilitation in a municipality framework.

Further attention by social work researchers and practitioners should be given to the appropriateness, effectiveness, and strategic implementation of technologybased mental health interventions within rehabilitation and recovery.

\section{Limitations}

The findings from this study should be interpreted with the following limitations in mind. First, it is a cohort study with a limited number of participants $(n=55)$. Second, since the study was conducted in a Danish context, other administrative and therapeutic social work with persons suffering from mental illness might affect the findings. Third, since this was a relatively short-term study, more research is needed to understand the long-term impact of tele-social rehabilitation.

\section{Conclusions}

Persons with mental illness who have been discharged from mental health treatment facilities find that participating in a tele-social-rehabilitation program gives them a sense of mobility, security, and the ability to develop new coping strategies in their everyday lives. However, participants also note that having the technology in their home gave them a feeling of surveillance. Future research is needed on longterm effects of tele-social rehabilitation.

\section{Acknowledgments}

We would like to thank the persons with mental illness for participating in interviews in the Video Assist project. We wish to thank Viewcare for providing the technical solutions used in this project. Thank you to Steven Samson for proofreading the manuscript.

Funding: This work was supported by Esbjerg Municipality, Department of Citizen Services and Labour Market, cofinancing from Aalborg - and Aarhus University.

\section{Footnote}

Reporting Checklist: The authors have completed the COREQ reporting checklist. Available at https://dx.doi. org/10.21037/mhealth-21-14

Data Sharing Statement: Available at https://dx.doi. org/10.21037/mhealth-21-14

Conflicts of Interest: All authors have completed the ICMJE uniform disclosure form (available at https://dx.doi. org/10.21037/mhealth-21-14). The authors have no conflicts of interest to declare.

Etbical Statement: The authors are accountable for all aspects of the work in ensuring that questions related to the accuracy or integrity of any part of the work are appropriately investigated and resolved. According to the Ethics Committee in the Region of North Jutland, Denmark (May 31 2013), the current study did not need ethical approval because the study did not involve any kind of new treatment for persons with mental illness. The study was conducted according to the Declaration of Helsinki (as revised in 2013). All participants signed informed consent agreements.

Open Access Statement: This is an Open Access article distributed in accordance with the Creative Commons Attribution-NonCommercial-NoDerivs 4.0 International License (CC BY-NC-ND 4.0), which permits the noncommercial replication and distribution of the article with the strict proviso that no changes or edits are made and the original work is properly cited (including links to both the formal publication through the relevant DOI and the license). See: https://creativecommons.org/licenses/by-nc-nd/4.0/.

\section{References}

1. Health at a Glance: Europe 2018. State of health in the EU cycle. Available online: https://ec.europa.eu/health/ sites/default/files/state/docs/2018_healthatglance_rep_ en.pdf

2. Christensen MK, Lim CCW, Saha S, et al. The cost of mental disorders: a systematic review. Epidemiol Psychiatr Sci 2020;29:e161.

3. Chan S, Parish M, Yellowlees P. Telepsychiatry Today. Curr Psychiatry Rep 2015;17:89.

4. García-Lizana F, Muñoz-Mayorga I. What about telepsychiatry? A systematic review. Prim Care Companion J Clin Psychiatry 2010;12:PCC.

5. Gaebel W, Lukies R, Kerst A, et al. Upscaling e-mental health in Europe: a six-country qualitative analysis and policy recommendations from the eMEN project. Eur Arch Psychiatry Clin Neurosci 2021;271:1005-16.

6. Hilty DM, Ferrer DC, Parish MB, et al. The effectiveness 
of telemental health: a 2013 review. Telemed J E Health 2013;19:444-54.

7. Reinhardt I, Gouzoulis-Mayfrank E, Zielasek J. Use of Telepsychiatry in Emergency and Crisis Intervention: Current Evidence. Curr Psychiatry Rep 2019;21:63.

8. Oestergaard CU, Dinesen B. Video communication as a tool for psychosocial support for people recovering from severe mental disorder: social workers' experiences. Mhealth 2019;5:38.

9. Ramsey AT, Montgomery K. Technology-based interventions in social work practice: a systematic review of mental health interventions. Soc Work Health Care 2014;53:883-99.

10. Hoffmann M, Wensing M, Peters-Klimm F, et al. Perspectives of Psychotherapists and Psychiatrists on Mental Health Care Integration Within Primary Care Via Video Consultations: Qualitative Preimplementation Study. J Med Internet Res 2020;22:e17569.

11. de Wit J, Dozeman E, Ruwaard J, et al. Web-based support for daily functioning of people with mild intellectual disabilities or chronic psychiatric disorders: A feasibility study in routine practice. Internet Interv 2015;2:161-8.

12. Anthony WA. Recovery from mental illness: The guiding vision of the mental health service system in the 1990s. Psychosoc Rehabil J 1993;16:11-23.

13. von Hippel E. Democratizing innovation. Cambridge, MA: MIT Press, 2005.

doi: $10.21037 /$ mhealth-21-14

Cite this article as: Oestergaard CU, Spindler H, Dinesen B. Video and social rehabilitation of persons with mental illness helps to structure everyday life: a qualitative study. mHealth 2022;8:4.
14. Yin RK. Case study research: Design and Methods. Thousand Oaks, California: SAGE Publications, 2014.

15. Delamont S. Ethnography and Participant Observation. In: Seale C, Gobo G, Gubrium JF, et al. (editors). Qualitative Research Practice. London: SAGE Publications Inc., 2007:605.

16. Kvale S, Brinkmann S. Interviews: Learning the craft of qualitative research. Thousand Oaks, CA: SAGE Publications, 2009.

17. Bashshur RL, Shannon GW, Bashshur N, et al. The Empirical Evidence for Telemedicine Interventions in Mental Disorders. Telemed J E Health 2016;22:87-113.

18. Hubley S, Lynch SB, Schneck C, et al. Review of key telepsychiatry outcomes. World J Psychiatry 2016;6:269-82.

19. Fletcher TL, Hogan JB, Keegan F, et al. Recent Advances in Delivering Mental Health Treatment via Video to Home. Curr Psychiatry Rep 2018;20:56.

20. How TV, Hwang AS, Green REA, et al. Envisioning future cognitive telerehabilitation technologies: a codesign process with clinicians. Disabil Rehabil Assist Technol 2017;12:244-61.

21. Calvillo J, Román I, Roa LM. How technology is empowering patients? A literature review. Health Expect 2015;18:643-52.

22. Campbell R, O'Gorman J, Cernovsky ZZ. Reactions of Psychiatric Patients to Telepsychiatry. Ment Illn 2015;7:6101. 